Roseli de Oliveira

Oㄱttps://orcid.org/0000-0003-3942-3986

Mauro Vitor Mendlowicz 2,3

Ohttps://orcid.org/0000-0002-8891-0548

William Berger²

OChtps:///orcid.org/0000-0001-7656-4548

Mariana Pires da Luz

OChttps://orcid.org/0000-0002-0297-5245

Carla Marques-Portella ${ }^{2}$

Onttps://orcid.org/0000-0001-7705-0549

Ivan Figueira ${ }^{2}$

Ohttps://orcid.org/0000-0002-8155-0519

Alexandre Xavier Gomes de Araújjo $0^{2,3}$

은tps://orcid.org/0000-0002-1298-8197

\section{Unnecessarily prolonged suffering: a case of missed diagnosis of post-traumatic stress disorder in a teaching hospital}

\author{
Sofrimento desnecessariamente prolongado: um caso de diagnóstico perdido \\ de transtorno de estresse pós-traumático em um hospital de ensino
}

DOI: 10.1590/0047-2085000000323

\begin{abstract}
We described a case in which a heavily-traumatized patient had been under psychiatric treatment for seven years (five of them in a university mental health clinic) but was never diagnosed with PTSD and, therefore, did not receive the proper treatment for a very long period. After the correct diagnosis was made and personalized treatment instituted, the patient has shown marked improvement in functionality and wellbeing. The key element in this case, was the adequacy of psychiatric training. Our report suggests that psychiatrists are not being adequately trained to identify traumatic events and to diagnose atypical cases of PTSD. With that in mind, we emphasize that theoretical modules on trauma and trauma-related disorders and practical training in specialized PTSD clinics should be incorporated into the psychiatric residency training programs wherever they may be missing, particularly in countries most impacted by violence. Furthermore, continuing medical education on trauma and PTSD should be provided by medical associations and journals to keep physicians updated on recent progress in the field.
\end{abstract}

\section{KEYWORDS}

PTSD, post-traumatic stress disorders, psychiatric training, delayed diagnoses, psychopharmacology.

\section{RESUMO}

Descrevemos o caso de um paciente gravemente traumatizado que estava em tratamento psiquiátrico há sete anos (cinco deles em uma clínica universitária de saúde mental), mas nunca foi diagnosticado com transtorno de estresse pós-traumático (TEPT) e, portanto, não recebeu o tratamento adequado por muito tempo. Após o diagnóstico correto e o tratamento personalizado instituído, o paciente mostrou melhora acentuada na funcionalidade e no bem-estar. O elemento-chave, neste caso, foi a adequação do treinamento psiquiátrico. Nosso relatório sugere que os psiquiatras não estão sendo treinados adequadamente para identificar eventos traumáticos e diagnosticar casos atípicos de TEPT. Com isso em mente, enfatizamos que os módulos teóricos sobre eventos traumáticos e transtornos relacionados ao trauma e treinamento prático em clínicas especializadas de TEPT devem ser incorporados aos programas de treinamento em residência psiquiátrica onde quer que ainda estejam ausentes, particularmente nos países mais afetados pela violência. Além disso, a educação médica continuada sobre trauma e TEPT deve ser fornecida por associações médicas e periódicos científicos para manter os médicos atualizados sobre os avanços recentes na área.

\section{PALAVRAS-CHAVE}

TEPT, transtorno de estresse pós-traumático, treinamento psiquiátrico, atraso diagnóstico, psicofarmacologia.
Received in: July/23/2020. Approved in: Jan/7/2021

1 Jurujuba Psychiatric Hospital, Niterói, RJ, Brazil.

2 Federal University of Rio de Janeiro (UFRJ), Institute of Psychiatry (IPUB), Rio de Janeiro, RJ, Brazil.

3 Federal Fluminense University (UFF), Department of Psychiatry and Mental Health, Niterói, RJ, Brazil.

Address for correspondence: Roseli de Oliveira. Rua João Paulo II, s/n, Alto da Bela Vista - 12630-000 - Cachoeira Paulista, SP, Brazil.

Telephone: +55 (12) 99123-7169. E-mail: roseliccn@yahoo.com.br 


\section{INTRODUCTION}

Post-traumatic stress disorder (PTSD) is a common and debilitating condition that may develop when a person is exposed either directly or indirectly to a traumatic event involving actual or threatened death, including serious injury and sexual violence. In the DSM-5, PTSD is characterized by four symptom clusters, namely: 1) intrusion symptoms associated with the traumatic event, such as recurrent distressing dreams or flashbacks; 2) avoidance symptoms, such as efforts to avoid distressing memories or external reminders; 3 ) negative alterations in cognitions and mood, such as persistent and exaggerated negative beliefs about oneself, others, or the world; and 4) arousal and reactivity symptoms, such as hypervigilance or irritable behavior. Each of the symptom clusters must be present for more than one month. Further, the individual must experience either clinically significant distress or impairment in an important area of functioning, such as the social, occupational or academic domains'.

Although the diagnosis of PTSD may seem straightforward, this condition often goes unnoticed. A recent review showed that current PTSD prevalence in primary care patients varied from $2 \%$ to $39 \%$, with the detection of PTSD by primary care physicians ranging from 0 to $52.1 \%^{2}$. Low detection rates for PTSD have been reported even among psychiatric outpatients assisted by well-trained psychiatrists. Howgego et al. described that a PTSD diagnosis was found in the medical records of only one of the 27 patients actually suffering from PTSD $(3.7 \%)^{3}$, while Mkize reported that none of the 18 patients with PTSD had been correctly diagnosed in their medical records 4 .

A recent study in a Brazilian university psychiatric outpatient clinic found that forty-one individuals (20.5\%) out of 200 patients were suffering from current PTSD, but only one of them (2.4\%) had this diagnosis recorded in his medical file. This study indicated that although PTSD may be highly prevalent among psychiatric outpatients, it is underdiagnosed even in teaching hospitals ${ }^{5}$ which are reputed to provide high-quality care ${ }^{6}$.

This paper aimed to describe the case of a heavily traumatized patient whose PTSD remained undiagnosed and thus deprived of proper treatment for seven years of continuous psychiatric care, including five years in a university psychiatric clinic. It also aimed to identify the reasons underlying the missed diagnosis and to suggest measures to prevent it.

\section{CASE REPORT}

Mr. A. is a 60-year old, Afro-Brazilian married bus driver with just primary education. In 2007, Mr. A. experienced three serious traumatic events within a single month. In the first one, he witnessed an out-of-control bus hitting and killing several of his regular passengers. A few days later, an armed robber tried to hold up the bus he was driving. Without giving a second thought, a very irritable Mr. A struck the man with a screwdriver several times. Finally, while driving in a freeway, Mr. A. saw a small out-of-control car swiveling sharply to the left and getting under the wheels of his fast-riding bus. He jumped out of the bus to help the victims but fainted soon afterward.

After a very brief respite, the patient found himself unable to drive buses and cars anymore. He felt that his "flesh trembled" violently without apparent cause and his "head spun". He could not sleep; when he finally managed to do so, he would be awakened by recurring nightmares in which he saw himself at the scene of the bus crash being chased by enraged people. Mr. A. had recurring, disturbing thoughts about the accident of which he could not get rid of. He avoided anything that could evoke the crash and trigger painful memories, from TV news to phone calls from concerned workmates expressing solidarity. Mr. A. felt deep sadness, strong discouragement, and difficulty concentrating. He lost interest in all previously pleasurable activities (e.g. soccer games) and isolated himself from family and friends. Mr. A. became very irritable, often losing his temper and engaging in nasty discussions with the closest relatives. In the midst of the discussions, he would sometimes smash objects, like cellphones. He was afraid of leaving home and watched cartoons on TV all day long without any enthusiasm.

Mr. A. started also hearing recurrent accusatory voices that told him that he was unworthy of living and therefore should kill himself. The voices convinced him "to end (the suffering) once for all". Mr. A. bought a rope planning to hang himself from a ceiling beam when there would be no one at home, but luckily, he never attempted it.

Mr. A. began his treatment still in 2007 in a local outpatient psychiatric clinic. During two years, he was medicated with risperidone 2 mg/day, levomepromazine 200 mg/day, carbamazepine 600 mg/day, promethazine 100 mg/day, diazepam $15 \mathrm{mg} /$ day, without much improvement. When his doctor quit the job, Mr. A. was referred to the outpatient clinic of a university psychiatric hospital. There, he was initially diagnosed with "anxious depression", and fluoxetine $20 \mathrm{mg} /$ day was added to his previous prescription.

For the next five years, Mr. A. continued to be seen on the university psychiatric hospital outpatient clinic at a monthly basis, where he was treated by successive classes of medical residents. In their written reports, we found that Mr. A. often referred to the traumatic events and their psychological consequences:

"...the images of the trauma come back to my mind and make me cry...", "...I tried to drive (his car), but I had tremors and intense fear...", "...I have constant thoughts 
about the robbery...", "...l often remember the robbery and the accident and feel 'chest tightness' and a 'tingling' that last for a long time...", "...l keep seeing those images of the accident in the head like a movie...", "...the bad news on television reminds me of the bus accident...", "... the voices talk about the accident and I remember a lot about what happened...", "...। see the people in the accident...", "... am hearing voices and watching 'a movie' in my head...".

The diagnosis was later changed to major depression with psychotic symptoms (DSM-IV 296.24) and histrionic personality disorder (DSM-IV 031.50). During this period, Mr. A. was treated with several classes of antidepressants (fluoxetine, imipramine, and paroxetine) and of antipsychotics (risperidone, fluphenazine, and haloperidol) and even with lithium, without any improvement.

In April 2014, an interested psychiatry resident brought the stalled treatment of Mr. A. to his supervisor's attention. The experienced psychiatrist immediately made the presumptive diagnosis of PTSD and had the patient referred to a specialized PTSD outpatient clinic. There, Mr. A. was assessed with the Structured Clinical Interview for DSM-IV (SCID-IV), which established the following current psychiatric diagnoses: 1) PTSD, 2) major depressive disorder single episode, severe with psychotic features, 3) panic disorder with agoraphobia and 4) obsessive-compulsive disorder. The baseline psychometric scores were: 1) Post-traumatic Stress Checklist - Civilian Version ${ }^{7}$ (PCL-C, for measuring the severity of post-traumatic symptoms) $=78$ (out of a maximum score of 85); 2) Beck Depression Inventory ${ }^{8}$ (BDI, for measuring the severity of depressive symptoms) $=39$ (out of a maximum score of 63), and 3) Beck Anxiety Inventory ${ }^{9}$ (BAl, for measuring the severity of anxiety symptoms) $=53$ (out of a maximum score of 63). The Trauma History Questionnaire ${ }^{10}$ confirmed the trauma reported in the clinical interview and also revealed an episode of sexual harassment at age 10, about which the patient felt deeply ashamed and would not acknowledge spontaneously.

Continued treatment with high doses of imipramine, haloperidol, topiramate (for irritability) and clonazepam (for insomnia) was found to be ineffective. In October 2014, clozapine was added to his therapeutic scheme due to the refractory auditory hallucinations and associated suicide risk. Incidentally, when a sample blood was drawn for the second time to monitor for the risk of agranulocytosis, Mr. A. said that his "blood was (visibly) contaminated with small white vermins" and asked for another sample to be drawn instead.

After nine months of treatment with slowly increasing doses of clozapine and progressive decrease of the hallucinations and the suicidality and improvement in sleep and irritability, Mr. A. witnessed a close acquaintance being murdered by mistake by policemen close to his home. This new traumatic event worsened his clinical condition dramatically. His scores at that time were as follows: PCL-C = $72, \mathrm{BDI}=45$, and $\mathrm{BAI}=46$.

In the twentieth month of follow-up at the PTSD clinic, Mr. A. was being medicated with clozapine $550 \mathrm{mg} /$ day, haloperidol $20 \mathrm{mg} /$ day, imipramine $250 \mathrm{mg} /$ day, topiramate $200 \mathrm{mg} /$ day and a small dose of clonazepam (0,5 mg/ night), since the medical team did not feel confident in discontinuing any medication. All hallucinations and suicidal ideation had disappeared. He had no more intrusive thoughts, sleep (including nightmares) was much improved, and the irritability - which was refractory to topiramate - had declined markedly. However, depressive symptoms were still significant. At this point, the recent availability of venlafaxine allowed this drug to be added to the therapeutic scheme.

One month after the adding of venlafaxine $75 \mathrm{mg} /$ day, Mr. A had already felt better and went for the first time in years to a mall. At this point, the patient was offered 18 sessions of cognitive behavioral therapy (CBT) but declined due to the long distance between the PTSD clinic and his home.

In the thirty-first month of follow-up at the PTSD clinic, Mr. A. suffered a new trauma (a bus accident) resulting in a transient return of insomnia and nightmares, but not of hallucinations or suicidal ideation. In the thirty-seven month of follow-up, the scores were as follows: $P C L-C=49, B D I=14$, and $B A I=20$ (see Figure 1). Although the PCL-C score was still relatively high, Mr. A. had reached a much-improved level of functionality and well-being. For the first time in years, the patient was able to leave home and run errands by bus alone. He no longer needed a chaperone to accompany him to the medical visits. Mr. A. found a new pleasure in visiting and playing with his young grandchildren. More surprisingly, he overcame the avoidance of driving completely and started taking his car out of the garage for short trips.

\section{DISCUSSION}

We described a case in which a recurrently traumatized patient had been under psychiatric treatment for seven years (five of them in a teaching hospital) but had never been diagnosed with PTSD and, in consequence, did not receive the recommended treatment. PTSD and its comorbidities tend to be refractory to treatment and the use of off-label medications is often mandated on a case-by-case basis, as it was the case of clozapine ${ }^{11}$. Constraints imposed by real-life circumstances, such as the temporary non-availability of the recommended drug venlafaxine ${ }^{12,13}$ due to logistical issues or the physical impossibility of attending CBT sessions regularly, also compound the difficulties of treating PTSD. As described in more details in the case report itself, a missed diagnosis of PTSD has many dire consequences: unnecessarily prolonged 


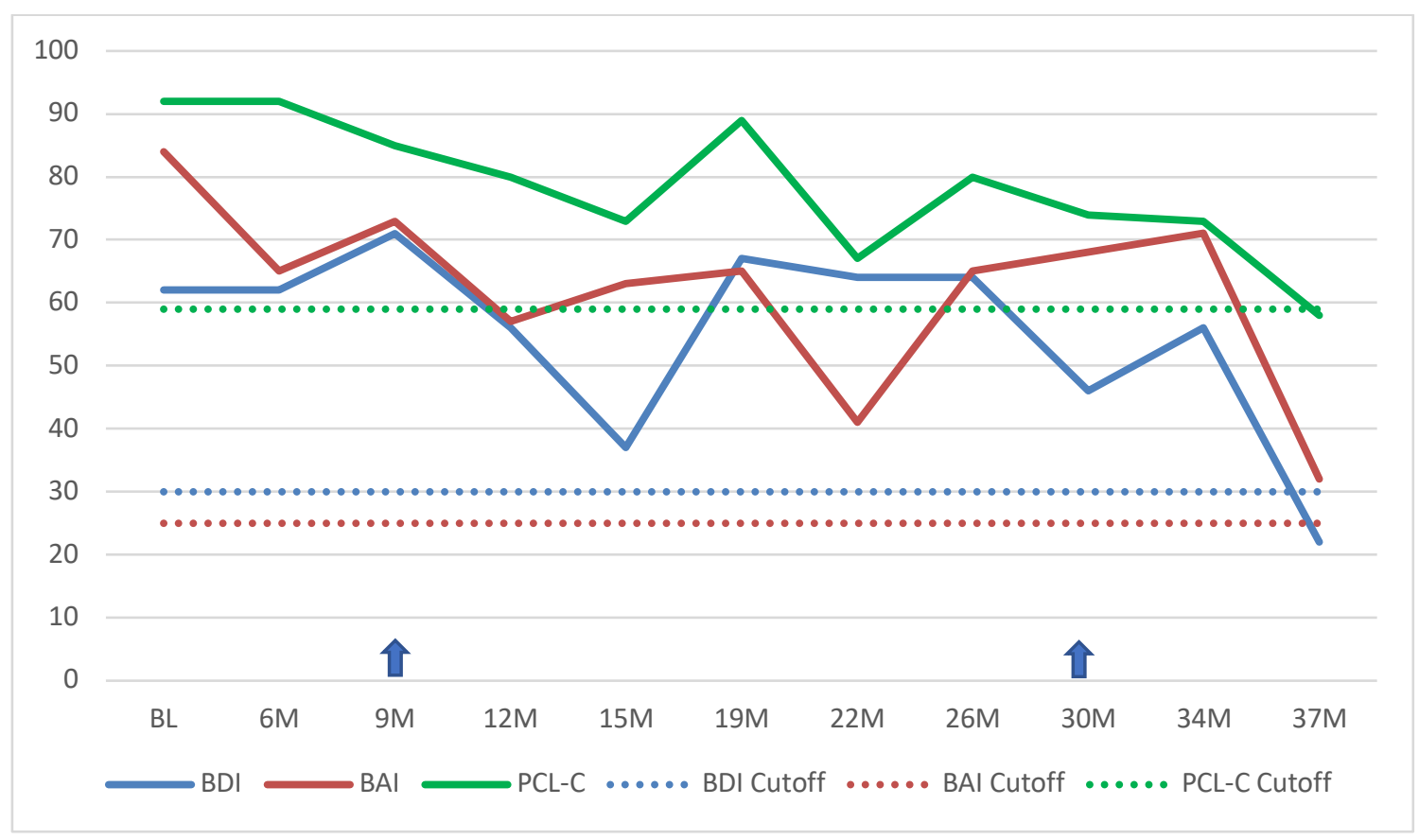

Figure 1. Patient's clinical improvement along the treatment in the PTSD clinic as measured by the PCL-C, BDI and BAl scores.

The figure 1 shows the psychometric evolution of the clinical status of the patient after admission to the PTSD outpatient clinic. Although initially all values were well above the cutoff point $(P C L-C=78, B D I=39, B A I=53)$, there was a gradual improvement with treatment. The effect of new traumatic events can also be seen. With the exception of the BAl, the final values were within the normality range. Blue arrows: new traumatic events. BL: baseline; M: month; PCL-C: Post-traumatic Stress Checklist - Civilian Version; BDI: Beck Depression Inventor; BAl: Beck Anxiety Inventory. PCL-C cutoff $=50$ points. BDI cutoff $=19$ points. BAl cutoff $=16$ points. Note: for the sake of comparability, raw data have been transformed into percentage of the maximum score of each scale.

suffering, suicidality, family stress, stigmatization, increased risk of domestic violence, loss of income, among others. The small literature available suggests that these cases are not rare ${ }^{5}$ and the present report may help us identify some factors contributing to this phenomenon.

A key issue in the present report is the adequacy of psychiatric training. The fact that PTSD has been included by the DSM-5 in a new independent chapter on Trauma- and Stressor-Related Disorders instead of being considered just one of the anxiety disorders in DSM-IV-TR acknowledges the increasing scientific and clinical relevance of this disorder. However, PTSD and traumatic events (including childhood abuse) may not yet be receiving the attention they deserve in psychiatric training. Psychiatrists in training (i.e. medical residents), who lack clinical experience, may be particularly prone to miss the diagnosis of PTSD for several reasons. PTSD patients themselves are often reluctant to talk about the traumatic events and to acknowledge their consequences due to the avoidance of distressing memories. Sensitive questioning may be required to elicit a history of trauma and symptoms of PTSD. Conventional history taking training, however, may have not yet fully internalized the impact of traumatic events, either in childhood or in adult life, upon mental health and, therefore, does not emphasize the careful assessment of their occurrence and consequences. The lack of knowledge about the epidemiology of PTSD may lead the examiner to overlook the degree of exposure to traumatic events in some occupations, like bus drivers working in crime-ridden neighborhoods ${ }^{14}$. The frequent comorbidity of PTSD with major depression, OCD and panic disorders is also often ignored. Prima facie presentation of PTSD in traumatized patients may not be the symptomatic tetrad described in DSM-5, but panic attacks or depressive symptoms ${ }^{15}$. In Mr. A.'s case, the most conspicuous symptom was the hallucinatory voices ordering him to kill himself. PTSD patients sometimes reported recurrent voices originating in external space and giving commands to commit self-harm and some individuals may act on these command hallucinations ${ }^{16}$. In the SCID interview, the auditory hallucinations were attributed to the comorbid major depressive episode with psychotic aspects. Either way, auditory hallucinations of this magnitude might lead inexperienced psychiatrists to make a wrong diagnosis of psychotic disorders or even of malingering and pay no heed to the patients' self-reports about traumatic events and post-traumatic symptoms. Clinical training with diagnostic instruments specific for post-traumatic symptoms, like the Post-traumatic Stress Disorder Checklist 5 (PCL-5), for traumatic events, such as Trauma History Questionnaire $(\mathrm{THQ})^{10}$ and the $\mathrm{LEC}^{7}$, and for childhood abuse and negligence, like the Childhood Trauma Questionnaire (CTQ) ${ }^{17}$, could help obviate diagnostic errors in such situations. 
In summary, our report suggests that psychiatrists are not being adequately trained to identify traumatic events and to diagnose atypical cases of PTSD. With that in mind, we emphasize that theoretical modules on trauma and traumarelated disorders and practical training in specialized PTSD clinics should be incorporated into the psychiatric residency training programs wherever they may be missing, particularly in countries most impacted by violence ${ }^{18,19}$. Furthermore, continuing medical education on trauma and PTSD should be provided by medical associations and journals to keep physicians updated on recent progress in the field.

\section{CONFLICTS OF INTEREST}

The authors report no conflicts of interest.

\section{REFERENCES}

1. American Psychiatric Association Diagnostic and Statistical Manual of Mental Disorders (DSM-5 ${ }^{\circledR}$ ). Arlington: American Psychiatric Publishing; 2013.

2. Greene T, Neria Y, Gross R. Prevalence, detection and correlates of PTSD in the primary care setting: a systematic review. J Clin Psychol Med Settings. 2016;23:160-80.

3. Howgego IM, Owen C, Meldrum L, Yellowlees P, Dark F, Parslow R. Posttraumatic stress disorder: an exploratory study examining rates of trauma and PTSD and its effect on client outcomes in community mental health. BMC Psychiatry. 2005;5:21.

4. Mkize DL. Post traumatic stress disorder symptoms in a psychiatric population not presenting with trauma: a preliminary study. Afr J Psychiatry (Johannesbg). 2008;11:51-3.

5. da Silva HC, Furtado da Rosa MM, Berger W, Luz MP, Mendlowicz M, Coutinho ESF, et al. PTSD in mental health outpatient settings: highly prevalent and under-recognized. Braz J Psychiatry. 2018;41:213-17.
6. Ayanian JZ, Weissman JS. Teaching hospitals and quality of care: a review of the literature. Milbank Q. 2002;80:569-93.

7. Lima EP, Vasconcelos AG, Berger W, Kristensen CH, Nascimento E, Figueira I, et al. Crosscultural adaptation of the Posttraumatic Stress Disorder Checklist 5 (PCL-5) and Life Events Checklist 5 (LEC-5) for the Brazilian context. Trends Psychiatry Psychother. 2016;38:207-15.

8. Wang YP, Gorenstein C. Psychometric properties of the Beck Depression Inventory-II: a comprehensive review. Rev Bras Psiquiatr. 2013;35:416-31.

9. Cunha JA. Manual da versão em português das Escalas Beck. São Paulo: Casa do Psicólogo; 2001.

10. Fiszman A, Cabizuca M, Lanfredi C, Figueira I. The cross-cultural adaptation to Portuguese of the Trauma History Questionnaire to identify traumatic experiences. Rev Bras Psiquiatr. 2005:27:63-6.

11. Wheatley M, Plant J, Reader H, Brown G, Cahill C. Clozapine treatment of adolescents with posttraumatic stress disorder and psychotic symptoms. J Clin Psychopharmacol. 2004;24:167-73

12. Davidson J, Baldwin D, Stein DJ, Kuper E, Benattia I, Ahmed S, et al. Treatment of posttraumatic stress disorder with venlafaxine extended release - A 6-month randomized controlled trial. Arch Gen Psychiatry. 2006;63:1158-65.

13. Hamner MB, Frueh BC. Response to venlafaxine in a previously antidepressant treatmentresistant combat veteran with post-traumatic stress disorder. Int Clin Psychopharmacol. 1998:13:233-4.

14. Tse JLM, Flin R, Mearns K. Bus driver well-being review: 50 years of research. Transp Res Pt F-Traffic Psychol Behav. 2006;9:89-114.

15. Brady KT. Posttraumatic stress disorder and comorbidity: recognizing the many faces of PTSD. J Clin Psychiatry. 1997;58(Suppl 9):12-5.

16. Waters F, Fernyhough C. Hallucinations: a systematic review of points of similarity and difference across diagnostic classes. Schizophr Bull. 2017;43:32-43.

17. Grassi-Oliveira R, Stein LM, Pezzi JC. Tradução e validação de conteúdo da versão em português do Childhood Trauma Questionnaire. Rev Saúde Pública. 2006;40:249-55.

18. Rosen RC, Ruzek JI, Karlin BE. Evidence-based training in the era of evidence-based practice: Challenges and opportunities for training of PTSD providers. Behav Res Ther. 2017;88;37-48.

19. Figueira I, Mendlowicz M. Diagnóstico do transtorno de estresse pós traumático. Rev Bras Psiquiatr. 2003;25(Supl I):12-6. 